\title{
The Effect of Water Repellent Surface Impregnation on Durability of Cement-Based Materials
}

\author{
Peng Zhang, ${ }^{1,2}$ Huaishuai Shang, ${ }^{1}$ Dongshuai Hou, ${ }^{1}$ Siyao Guo, ${ }^{1}$ and Tiejun Zhao ${ }^{1}$ \\ ${ }^{1}$ Center for Durability \& Sustainability Studies, Qingdao University of Technology, Qingdao 266033, China \\ ${ }^{2}$ Institute of Concrete Structures and Building Materials, Karlsruhe Institute of Technology, 76131 Karlsruhe, Germany \\ Correspondence should be addressed to Peng Zhang; zhp0221@163.com and Huaishuai Shang; shanghuaishuai@aliyun.com
}

Received 14 April 2017; Accepted 22 June 2017; Published 25 July 2017

Academic Editor: Jun Liu

Copyright (c) 2017 Peng Zhang et al. This is an open access article distributed under the Creative Commons Attribution License, which permits unrestricted use, distribution, and reproduction in any medium, provided the original work is properly cited.

\begin{abstract}
In many cases, service life of reinforced concrete structures is severely limited by chloride penetration until the steel reinforcement or by carbonation of the covercrete. Water repellent treatment on the surfaces of cement-based materials has often been considered to protect concrete from these deteriorations. In this paper, three types of water repellent agents have been applied on the surface of concrete specimens. Penetration profiles of silicon resin in treated concrete have been determined by FT-IR spectroscopy. Water capillary suction, chloride penetration, carbonation, and reinforcement corrosion in both surface impregnated and untreated specimens have been measured. Results indicate that surface impregnation reduced the coefficient of capillary suction of concrete substantially. An efficient chloride barrier can be established by deep impregnation. Water repellent surface impregnation by silanes also can make the process of carbonation action slow. In addition, it also has been concluded that surface impregnation can provide effective corrosion protection to reinforcing steel in concrete with migrating chloride. The improvement of durability and extension of service life for reinforced concrete structures, therefore, can be expected through the applications of appropriate water repellent surface impregnation.
\end{abstract}

\section{Introduction}

The development of cement and concrete dates to the mid1800 s, and it proved to be a revolutionary innovation in building materials. Today, reinforced concrete is the single most widely used building material in the world for both entire buildings and key structural elements that need to be able to withstand various substantial loads. Reinforced concrete is used in such large amounts because it shares the characteristics of relatively good durability, low maintenance cost, and convenience. However, it is nowadays generally accepted that service life of many reinforced concrete structures is frequently not sufficient. The cost for early repair measures is often significantly higher than the cost for new construction. The major origin of these problems of maintenance and repair costs and poor serviceability is a lack of durability for reinforced concrete structures [1-3].

Moisture transport in cement-based materials is a crucial physical process for their durability since many effects that influence the durability of the building structure are induced by water itself as well as harmful substances transported by it. If cement-based materials, such as mortar and concrete, are exposed to water, a series of deteriorating processes can take place. One dominant process or a combination of different processes may eventually limit the expected service life of reinforced concrete structures. The corrosive attack of water with respect to concrete can be subdivided at least into three different types. First, pure water in permanent contact with cement-based materials acts as a solvent. The binding matrix consisting of $\mathrm{Ca}(\mathrm{OH})_{2}$ and C-S-H gel is gradually dissolved by hydrolysis. Second, gases of the environment may be dissolved in the aqueous pore solution of concrete. In this way, acids are formed, for instance, by dissolution of $\mathrm{CO}_{2}$ and $\mathrm{SO}_{2}$, which could react rapidly with the hydration products of cement. In the third type of corrosive attack water acts essentially as a vehicle and transports dissolved compounds, such as chloride ions, into the porous system of cementitious matrix. Besides the corrosive attacks, water also plays an 


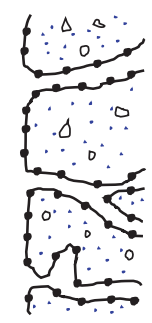

(a) (b)

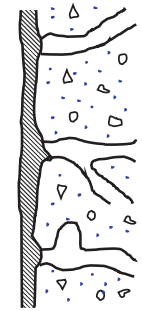

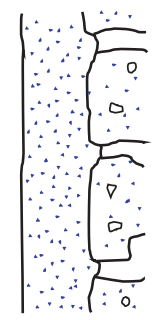

(c)
FIGURE 1: Types of surface treatments: (a) impregnation; (b) coating; and $(c)$ cementitious coating surface.

important role in some other physical and chemical damage for concrete, such as freeze-thaw action, alkali-aggregate reaction, steel corrosion, and drying shrinkage.

It is obvious that all these three types of aggressive attacks just mentioned act from the surface of concrete. Throughout history, a range of protective materials have been applied to the exposed surfaces of structural concrete elements to prevent the ingress of water, including oils, waxes, or paints. Nowadays big progress has been achieved in the production of water repellent agents and development of water repellent treatment. It has been proved that surface impregnation by water repellent agents should be an effective preventive method for concrete structures [4-9]. For broader information about the studies on water repellent treatment, the proceedings of HYDROPHOBE conference series (Hydrophobes I-VIII) can be known from [10-17].

In this contribution, the basic mechanism of water repellent treatment on cement-based materials has been briefly described. Three types of water repellent agents which are in forms of liquid, cream, and gel have been applied on the surface of two types of cement-based materials. The consequent effects of surface impregnation on reducing water capillary suction, chloride penetration, carbonation, and reinforcement corrosion in concrete will be measured and discussed.

\section{Basic Mechanism of Water Repellent Treatment}

In general, water repellent surface treatments are mainly classified in three groups according to the mechanism by which the protection is achieved. In Figure 1, types of surface treatments are illustrated according to this classification [18]. Surface treatment by silanes belongs to "impregnation," whose basic mechanisms are given in the next two paragraphs.

The most important silicon-based water repellent agents are those made of silanes and siloxanes which are polymers containing three alkoxy groups, denoted $\mathrm{OR}^{\prime}$, linked to a silicon atom, with each silicon atom carrying an organic alkyl group, denoted $\mathrm{R}$. The silicon functional alkoxy group reacts with water and yields a reactive silanol group (hydrolysis stage). Further condensation by crosslinking to the hydroxyl groups forms polysiloxane (silicon resin) as the active water repellent product which is linked to the inorganic substrate by way of covalent siloxane bonds, as shown in Figure 2.

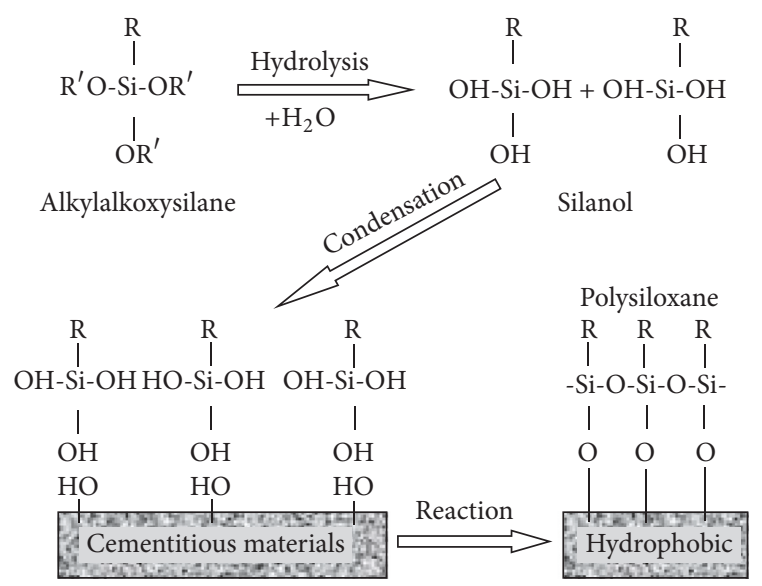

Figure 2: Mechanisms for hydrolysis and polymerization of silane in cement-based materials.

The organofunctional alkyl groups will reduce the critical surface tension of the material surface and thus provide hydrophobicity, while the silicon functional groups provide reactivity with the substrate and control the penetration depth.

The effect of water repellents is essentially based on their low surface tension. The behaviour of water when contacting the surface of a material is governed by the surface tension which can be measured by the contact angle, as shown phenomenologically in Figure 3. The intensity of the water repellent property is associated with the contact angle between water and the treated surface. Contact angles of a water droplet of more than $90^{\circ}$ represent hydrophobic property with less than $90^{\circ}$ hydrophilic property. The higher the contact angle is, the more water repellent the surface becomes. The hydrophobicity of water repellents is in fact realized in two steps. Firstly, the beading effect causes the water droplet to quickly run off and leave the surface. Secondly, when water tends to spread and form a water film over the surface, water absorption is reduced by excluding via treated capillaries.

\section{Materials and Methods}

3.1. Materials and Preparation of Specimens. Two types of mortar and concrete specimens were prepared for the test series. Ordinary Portland cement type 42.5 , crushed aggregates with a maximum diameter of $20 \mathrm{~mm}$ and density of $2620 \mathrm{~kg} / \mathrm{m}^{3}$, and river sand with a maximum grain size of $5 \mathrm{~mm}$ and density of $2610 \mathrm{~kg} / \mathrm{m}^{3}$ were used. The exact compositions of the concrete used in this project are given in Table 1 . The mix with $\mathrm{W} / \mathrm{C}=0.5$ was named concrete $\mathrm{C}$. Mortar with a higher water-cement ratio $(\mathrm{W} / \mathrm{C}=0.6)$ was also prepared and called mortar M. Some specimens prepared with both concrete $\mathrm{C}$ and mortar $\mathrm{M}$ were later surface impregnated with different amount of water repellent agents. The concrete specimens were used for water absorption test, chloride penetration test, carbonation test and steel corrosion test. The mortar specimens were prepared only for neutron radiography test in order to avoid the influence of course aggregate during the image analysis. 


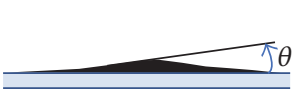

(a)

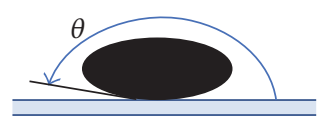

(b)

Figure 3: The principle of water repellency: (a) untreated concrete, contact angle $\theta$ less than $90^{\circ}$; (b) water repellent treated, contact angle $\theta$ greater than $90^{\circ}$.

TABle 1: Composition of the two types of mixtures used in this project, $\mathrm{kg} / \mathrm{m}^{3}$.

\begin{tabular}{lccccc}
\hline Type & W/C & Cement & Sand & Aggregate & Water \\
\hline Concrete C & 0.5 & 320 & 653 & 1267 & 160 \\
Mortar M & 0.6 & 300 & 1650 & - & 180 \\
\hline
\end{tabular}

From all mixes given in Table 1 cubes with side length of $100 \mathrm{~mm}$ were produced. Another type of prismatic specimens with dimensions of $280 \times 150 \times 115 \mathrm{~mm}$ with two steel bars was also prepared for steel corrosion test. All specimens were compacted in steel forms and cured for one day before demolding. After that the specimens were moved into a curing room $\left(T=20 \pm 2^{\circ} \mathrm{C}, \mathrm{RH}>95 \%\right)$. At an age of 28 days they were taken out of the curing room for water repellent surface treatment.

3.2. Water Repellent Surface Impregnation. After 28 days of moist curing, the specimens were further stored at $\mathrm{RH}$ of $60 \%$ for 7 days for drying. Then one of the molded surfaces of cubic specimens and the top surface $(280 \times 115 \mathrm{~mm})$ of the rectangular parallelepiped specimens have been impregnated with three different types of water repellent agents. The agents' type, usage amount, and the corresponding samples codes are listed in Table 2. After that the specimens were stored again at $\mathrm{RH}$ of $60 \%$ for another 7 days in order to allow sufficient polymerization of silane. Then the surface impregnated specimens were ready for further tests.

One series have been impregnated with liquid silane. In this case, concrete surface was put in contact with liquid silane for one hour. During this period, liquid silane could be absorbed into specimen due to capillary suction. In second series one of the molded surfaces was covered by silane cream. The amount of usage on the surface was $400 \mathrm{~g} / \mathrm{m}^{2}$. For the third to fifth series, 100,400 , and $600 \mathrm{~g} / \mathrm{m}^{2}$ of silane gel were applied. Both silane cream and gel were covered on the concrete surfaces with a small brush.

From the specimens treated by water repellent agents, layers from the treated surface with a thickness of $1 \mathrm{~mm}$ each have been milled consecutively by means of a specially built milling cutter. The powder obtained from this process was collected. The silicon content of these powders was then determined by means of FT-IR spectroscopy. This method has been developed and further refined for this specific application by Gerdes and Wittmann [19].

3.3. Water Absorption and Chloride Penetration. Water absorption of surface treated and untreated specimens has been measured by a standard method [20]. Before the test, the

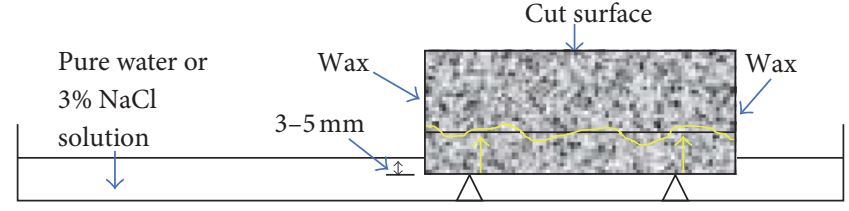

FIGURE 4: Schematic illustration for water absorption and chloride penetration test of concrete.

cubic specimens were cut into two halves and dried in a ventilated oven at a temperature of $50^{\circ} \mathrm{C}$ for 7 days until mass equilibrium was reached. When the specimens cooled down to the room temperature the treated and untreated specimens were put in contact with water for selected periods of time, as shown in Figure 4. Then the amounts of absorbed water by capillary suction were measured by weighing the specimens after 1, 2, 4, 8, 24, 48, and 72 hours.

In a similar way as described in the last paragraph, chloride penetration test $(3 \% \mathrm{NaCl}$ solution) for water repellent treated and untreated specimens were carried out for 28 days. After the test, powder was milled consecutively starting at the specimens' surface which had been exposed to salt solution. The chloride content of the powder was then determined with the ion selective electrode method. In this way, the chloride profiles in water repellent surface impregnated and untreated specimens have been determined.

3.4. Neutron Radiography. Water repellent mortar specimens and untreated companion specimens were also tested by neutron radiography at Paul-Scherrer-Institute (PSI) in Switzerland. Neutron radiography has been identified as an ideal and unique nondestructive technique to study water movement and moisture distributions in cement-based materials because of their strong attenuation by hydrogen and their insensitivity to the dominant ingredients, such as silica and calcium in cement-based materials. More details about this technique can be found in [21-26].

First, neutron images were taken on samples, which were in hygral equilibrium with the room atmosphere $(\mathrm{RH} \approx$ $60 \% ; T \approx 20^{\circ} \mathrm{C}$ ). Then neutron images were taken again on water repellent treated and untreated mortar specimens after contact with water for 0.5 and 2 hours. In this way, the water movement in samples was visualized. In addition, some surface impregnated and untreated samples were placed in water for three days. This period was sufficient to saturate the samples completely. Then neutron images were taken on these water saturated specimens. Both untreated and surface impregnated mortar specimens in the water saturated state 
TABLE 2: Three types of water repellent agents used in this project and their uses.

\begin{tabular}{lccc}
\hline & Type & Amount of use & Note \\
\hline Ref. & - & - & No treatment, reference sample \\
L1 & Liquid silane & $470 \mathrm{~g} / \mathrm{m}^{2}$ & Surface absorption \\
C400 & Silane cream & $400 \mathrm{~g} / \mathrm{m}^{2}$ & Surface brushing \\
G100 & Silane gel & $100 \mathrm{~g} / \mathrm{m}^{2}$ & Surface brushing \\
G400 & Silane gel & $400 \mathrm{~g} / \mathrm{m}^{2}$ & Surface brushing \\
G600 & Silane gel & $600 \mathrm{~g} / \mathrm{m}^{2}$ & Surface brushing \\
\hline
\end{tabular}

were investigated. From the neutron images the moisture distribution can be analyzed quantitatively.

3.5. Accelerated Carbonation. After drying in lab for 7 days, both surface treated and untreated specimens were submitted to accelerated carbonation for 7 and 28 days. According to the Chinese standard [27], the concentration of $\mathrm{CO}_{2}$ gas was maintained constant at $20 \pm 2 \%$; relative humidity in carbonation box was about $70 \%$; the temperature was $20 \pm 3^{\circ} \mathrm{C}$. Four surfaces except for the treated surface and its opposite surface had been sealed with wax before being placed in carbonation situation. In this way carbonation normal to two opposite surfaces into concrete was imposed. After 7 and 28 days, carbonation depth in the surface impregnated and untreated samples were measured by spraying phenolphthalein solution with $1 \%$ in ethanol.

3.6. Reinforcement Corrosion. This test followed ASTM G 109-07 [28]; specimens were $280 \times 150 \times 115 \mathrm{~mm}$ with a reservoir of $\mathrm{NaCl}$ solution on the test surface. The reservoir with size of $150 \times 75 \times 75 \mathrm{~mm}$ was located at the center of top surface. Upper reinforced steel was positioned $20 \mathrm{~mm}$ from ponded surface and bottom steels were $25 \mathrm{~mm}$ from bottom surface. The ends of steel were protected with electroplater's tape and a $200-\mathrm{mm}$ portion in the middle is bare. During the test, the half-cell potential and the corrosion current density of the steel rebar in surface impregnated and untreated concrete specimens were measured continuously every week.

\section{Results and Discussion}

4.1. Effect of Water Repellent Surface Impregnation on Water Absorption. Water absorption of both untreated and surface treated concrete specimens has been measured for 72-hour contact with water. Results obtained at different time are shown in Figure 5. Points indicated in Figure 5 are average values of three independent measurements. The variation of the individual measurements is also shown. It can be learned from the results that all the surface impregnated concrete absorbed much less water compared to the untreated concrete. In this case, it is not liquid water but water vapor is trapped by capillary condensation once it has crossed the silane impregnated layer. In addition, capillary condensation can take place in nanopores of concrete, as silane molecules cannot enter these narrow spaces because of geometrical reasons. Therefore, a small amount of capillary condensed water still can migrate into the pores by diffusion. But, compared to the untreated concrete, the amount of absorbed

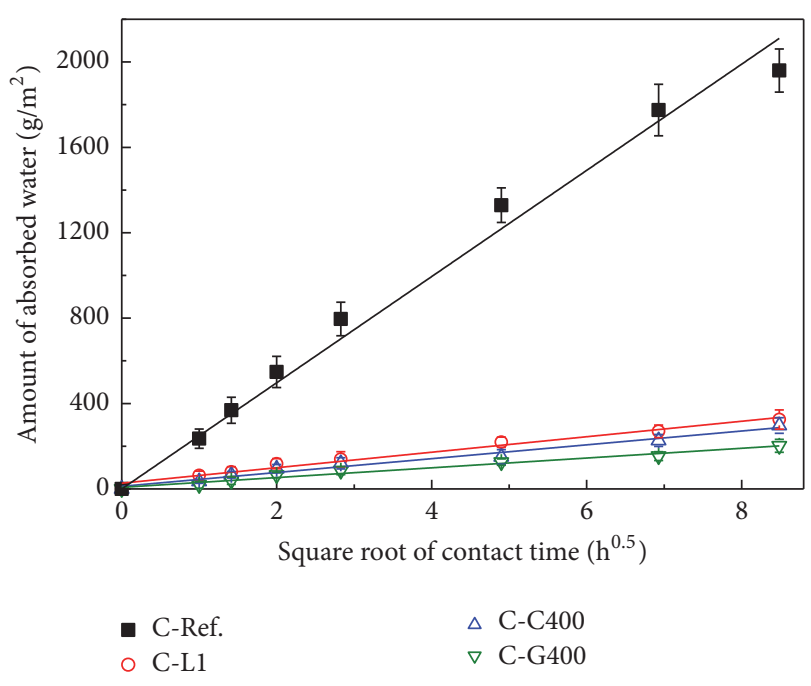

FIGURE 5: The amount of absorbed water in surface impregnated and untreated concrete at different time of water absorption and the linear fitting lines.

water is reduced significantly by surface impregnation with each type of silane.

For a homogeneous porous material, a simple expression can be deduced from theory of capillarity to describe capillary suction as function of time; see (1) $[29,30]$. This equation is only a first approximation because the skin effect of concrete will always be the origin of a deviation of measured results from the theoretical prediction.

$$
\Delta W=A \sqrt{t}
$$

where $\Delta W$ stands for the amount of absorbed water by capillary suction per unit area and $t$ for the duration of contact. $A$ is the coefficient of capillary suction. The coefficient of capillary suction deduced from Figure 5 for treated and untreated concrete can be calculated. The results indicate that the coefficient of capillary suction for untreated sample is $248.7 \mathrm{~g} /\left(\mathrm{m}^{2} \mathrm{~h}^{0.5}\right)$, while for sample L1 (impregnated by liquid silane) it is $40.9 \mathrm{~g} /\left(\mathrm{m}^{2} \mathrm{~h}^{0.5}\right)$, approximately one-sixth of untreated sample; for samples C400 (silane cream) and $\mathrm{G} 400$ (silane gel) the coefficients are 34.5 and $24.5 \mathrm{~g} /\left(\mathrm{m}^{2} \mathrm{~h}^{0.5}\right)$, respectively. They are less than one-seventh and one-tenth of that of untreated sample. This obviously indicates that surface impregnation with water repellent silanes can significantly reduce water penetration into concrete. 


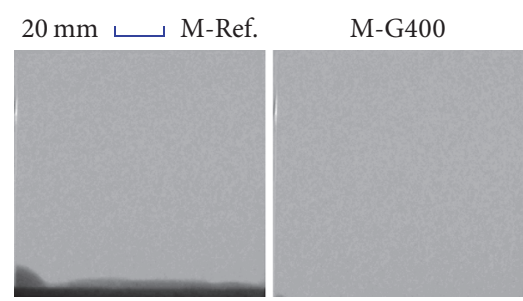

(a) Neutron image after 0.5 hours

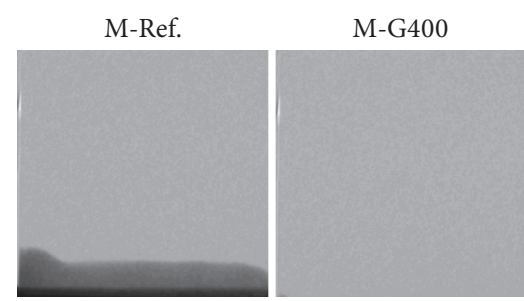

(b) Image after 2 hours

FIGURE 6: Observations of water penetration into mortar specimens after 0.5 and 2 hours by means of neutron radiography.

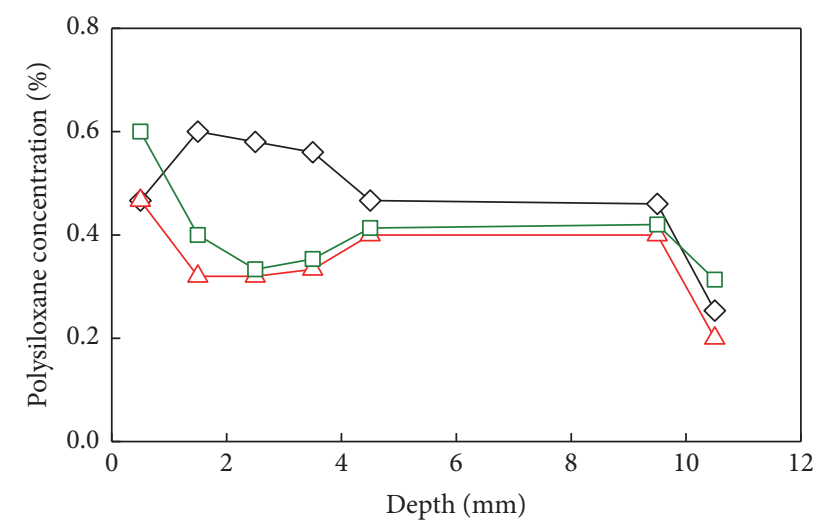

$\begin{array}{ll}\prec & \text { C-L1 } \\ \triangle & \text { C-C400 } \\ \square & \text { C-G400 }\end{array}$

FIGURE 7: Polysiloxane profiles in water repellent treated concrete with silane liquid, silane cream, and silane gel.

Figure 6 shows the visual observation of water penetration into untreated and water repellent surface treated mortar specimens after 0.5 and 2 hours by means of neutron radiography. It can be clearly seen that after half an hour of contact with water a penetration front becomes visible in untreated concrete. This irregular front gradually moves into the porous material with increasing of time. But for the surface impregnated sample water uptake could not be observed with the naked eyes even after two hours because of the polysiloxane film formed from silane, which made the near-surface region hydrophobic.

After being applied on the surfaces of concrete silane penetrated and formed polysiloxane (silicon resin) in the near-surface zone. The polysiloxane concentration in surface impregnated samples has been measured by FT-IR spectroscopy. The results are shown in Figure 7. It can be seen that in each case a penetration depth of about nine millimeters has been reached. This treatment can be called deep impregnation in contrast to simple surface impregnation. In some cases, a simple surface impregnation is sufficient. However, to build up a reliable and durable chloride barrier, a minimum penetration depth of $7 \mathrm{~mm}$ is often required [5]. This has to be confirmed in the context of quality assurance after surface treatment in practice. If the penetration depth is too small, the ingress of aggressive ions with water is slowed down but not prevented for long time.

In addition, neutron images of three types of impregnated and water saturated mortar specimens are shown in Figure 8. The upper impregnated surface is of interest exclusively in this context. It can be clearly seen with the naked eye that the neutron transmission is significantly higher in the outer impregnated layer. The thickness of the impregnated layer can be estimated from the results shown in Figure 8. The average values determined by visual inspection are 2.0, 4.1, and $6.3 \mathrm{~mm}$ for samples G100, G400, and G600, respectively.

The moisture distribution was further measured in the near-surface zone as indicated with the rectangular frame shown in Figure 8 (M-G600) from the neutron images obtained from water saturated specimens. Results are shown in Figure 9. As expected, the moisture content in the untreated specimen is essentially homogeneously distributed all over the volume. The observed slight decrease of water content close to the surface may be attributed to a small water loss during handling before taking the first neutron image.

However, on the surface impregnated specimens, the influence of the water repellent near-surface zone can be observed clearly. As expected, the water content in the water repellent zone is significantly reduced. The width of the water repellent zone can also be observed clearly. In samples $\mathrm{M}$ G100 a water repellent layer with a thickness of approximately $2 \mathrm{~mm}$ has been established. In samples M-G400 and MG600 the thickness of the water repellent zone can be estimated to be approximately 4 and $6 \mathrm{~mm}$ respectively. What is most important, however, is the fact that in sample MG100 the water content in the water repellent zone is certainly substantially reduced but still a certain amount of water can be observed in this region. In contrast in sample M-G600 a minimum amount of water can be detected only. From these results, it can again be concluded that deep impregnation is necessary for an efficient chloride barrier.

\subsection{Effect of Water Repellent Surface Impregnation on Chloride} Penetration. The surfaces of treated and untreated concrete specimens have been brought in contact with an aqueous $\mathrm{NaCl}$ solution with concentration of $3 \%$ for 28 days. The chloride profiles were determined. The results are shown in Figure 10. It can be seen that a lot of chloride ions penetrated into untreated concrete even up to depth of $30 \mathrm{~mm}$. It already has been shown that capillary suction is a most powerful mechanism for the transport of chlorides into concrete. If 


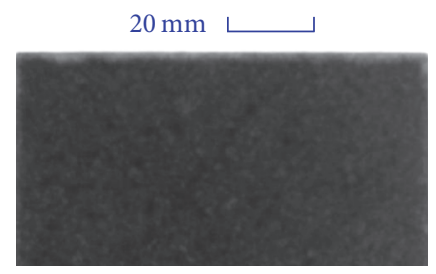

(a) M-G100

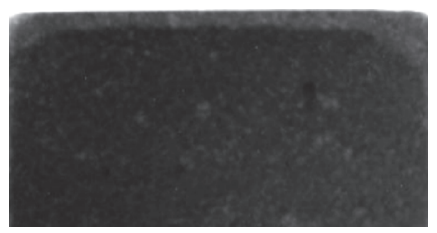

(b) M-G400

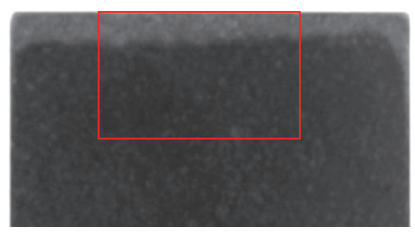

(c) M-G600

Figure 8: Neutron images as obtained on the tree types of water repellent surface impregnated and water saturated mortar specimens. The upper half of the neutron images taken on square slabs is shown only.

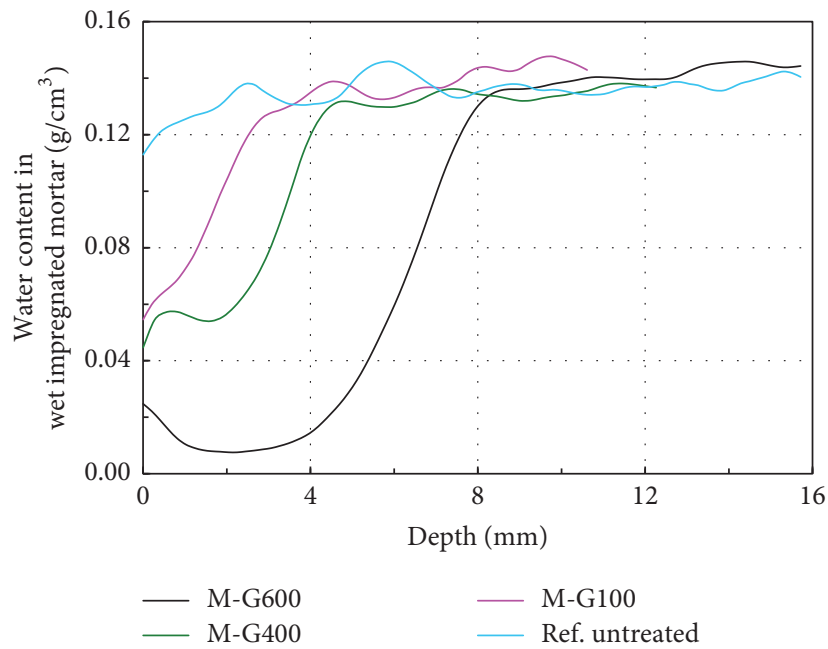

FIGURE 9: Water content in surface impregnated and water saturated mortar specimens G100, G400, and G600. For comparison, the water distribution in untreated mortar is also shown.

there is no capillary action, salt solution cannot be taken up by the porous material and if the micropores are not water filled chloride cannot diffuse into the porous structure either. Therefore, by means of surface impregnation with silanes it restrained water from penetrating into concrete and consequently prevented chloride migration. During the exposure period for treated concrete no chloride has penetrated into deep part of the material. The small amount of chloride ions which can be detected in the first $3 \mathrm{~mm}$ is due to surface roughness and open big pores in the near-surface zone. Therefore, surface impregnation with silane is an efficient chloride barrier for porous cement-based materials.

\subsection{Effect of Water Repellent Surface Impregnation on Carbon-} ation. After 7 and 28 days of carbonation, the carbonation depth of water repellent treated and untreated concrete has been measured. The results are shown in Figure 11. It can be obviously found that surface impregnated specimens have lower carbonation depth than untreated concrete. Among the surface treatments, application of $400 \mathrm{~g} / \mathrm{m}^{2}$ silane cream and silane gel reduces approximately one half of carbonation depth compared to the reference concrete, whose efficiency is much better than $100 \mathrm{~g} / \mathrm{m}^{2}$ covering usage.

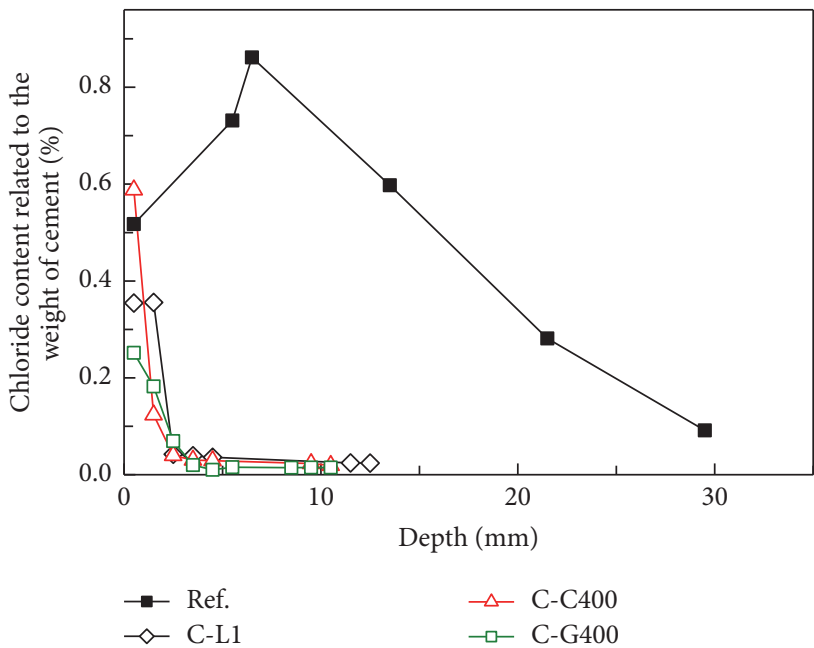

FIGURE 10: Chloride profiles of surface impregnated and untreated concrete after continuous contact with $\mathrm{NaCl}$ solution for 28 days.

By surface impregnation with silanes, the hydrophobic film protects concrete from water penetration, which usually makes the hydrophobic layer almost dry. Very little carbonation action takes place in this area because the neutralization between $\mathrm{CO}_{2}$ gas and calcium hydrate or C$\mathrm{S}-\mathrm{H}$ gel needs water, while this layer also makes the moisture diffusion of concrete very low and consequently makes the area behind the hydrophobic layer moist, under which condition carbonation cannot happen either. However, it must be noticed that the conclusion that surface impregnation reduces carbonation depth by about one half was obtained under $\mathrm{RH}$ of $70 \%$ in the carbonation box. If the environment is very dry, the untreated concrete would lose water very soon; but, in the treated concrete, the drying rate is slowed down and consequently liquid water in the pores would make carbonation process quicker [31].

4.4. Effect of Water Repellent Surface Impregnation on Reinforcement Corrosion. The half-cell potential $\left(\mathrm{Cu}-\mathrm{CuSO}_{4}\right)$ and corrosion current density of the steel rebar in reinforced concrete have been measured. The results are shown in Figure 12. It indicates clearly that the concrete specimens without surface impregnation exhibits high level of negative corrosion potentials and corrosion current densities, especially after approximately 33 weeks of exposure period. At this stage, 


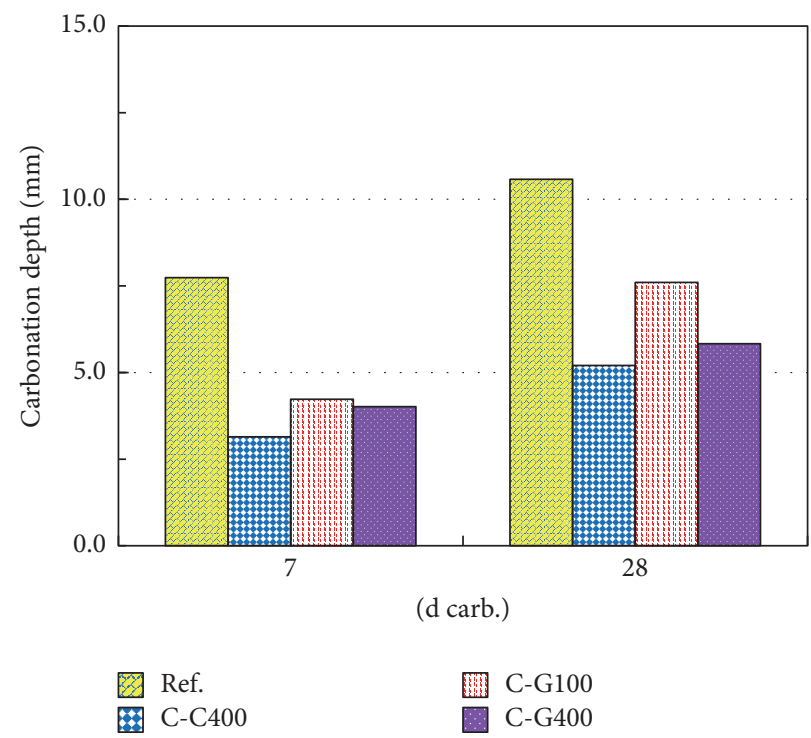

FIGURE 11: Carbonation depth of untreated and surface impregnated concrete after 7 and 28 days of accelerated carbonation.

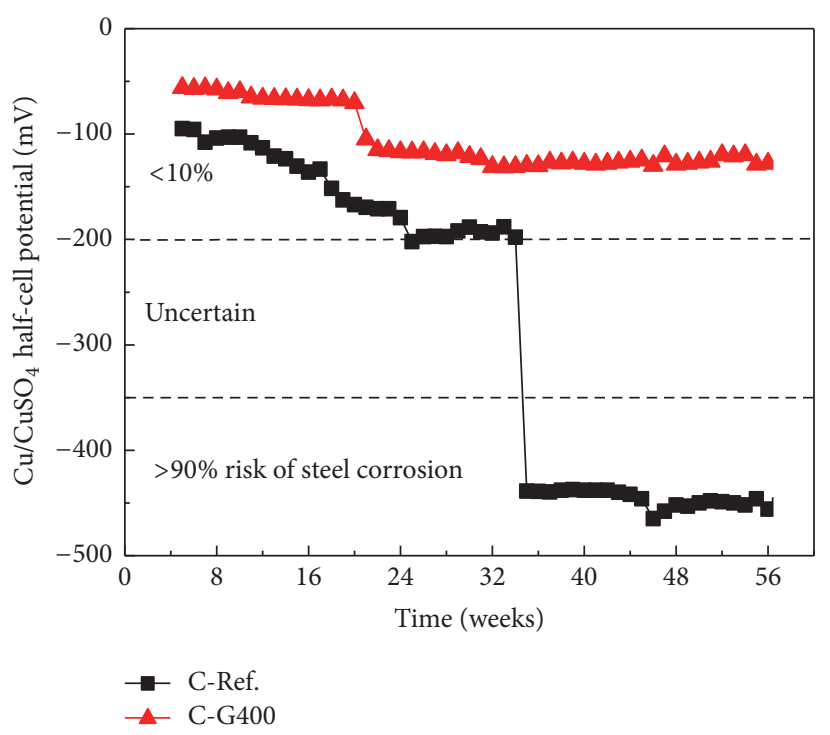

(a) $\mathrm{Cu}-\mathrm{CuSO} 4$ half-cell potential

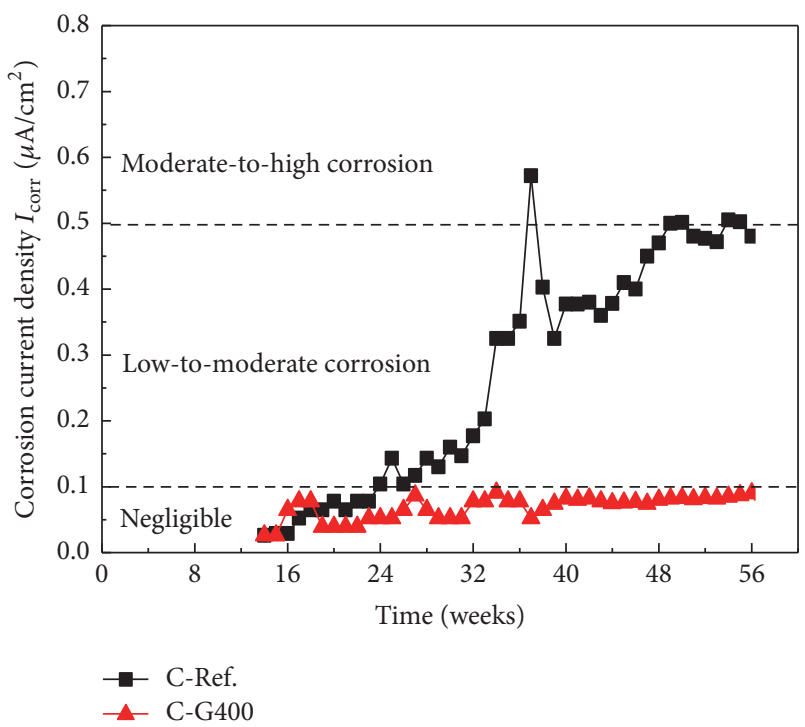

(b) Corrosion current density

FIGURE 12: $\mathrm{Cu}-\mathrm{CuSO}_{4}$ half-cell potential (a) and corrosion current density (b) of reinforced steel in reference untreated and surface impregnated concrete by silane.

the corrosion potential was about $-460 \mathrm{mV}$. According to the ASTM standard, this means the risk of corrosion was greater than $90 \%$ [32]. The corrosion current density was about $0.4 \sim$ $0.5 \mu \mathrm{A} / \mathrm{cm}^{2}$ which means the steel reinforcement started to corrode, while, for water repellent surface treated concrete, both the electric potential and corrosion current density were kept much lower throughout the period measured. The risk of corrosion was maintained lower than $10 \%$ from the results of corrosion potential. From the results of corrosion current density, corrosion can be neglected. This shows that corrosion did not happen in water repellent treated specimens. Therefore, corrosion activities can be reduced considerably by surface impregnation.

\section{Conclusions}

Based on the results presented herein, the following conclusions can be drawn.

(1) When the surface of water repellent treated concrete is in contact with water, there is no aqueous water penetration; but small amount of water vapor is still absorbed and condenses in the untreated pores of the material. Therefore, 
the hydrophobic layer with several millimeters of thickness can reduce significantly water absorption into concrete.

(2) Water vapor, however, does not contribute to ion transport. If the pores of concrete are not water filled, ions diffusion is slowed down effectively. Hence surface impregnation with silane provides an effective chloride barrier. As a consequence, the service life of a concrete structure exposed to sea water or deicing salt can be extended.

(3) Carbonation depth of surface impregnated concrete can be reduced one half under the environmental $\mathrm{RH}$ of $70 \%$ compared to the untreated concrete.

(4) Surface impregnation with silanes also provides effective corrosion protection to reinforcing steel in concrete contacted with chloride solution. In order to prolong the service life of reinforced concrete structures, water repellent treatment can be taken into consideration to reduce the risk of steel corrosion, provided surface treatment is adequately maintained which can be achieved by appropriate application and deep impregnation ( $>6 \mathrm{~mm}$ ) [33]. In addition, the durability of silane impregnation itself and its long-term residual protection has to be studied. In this sense, the efficiency of the protective measure should be controlled in regular intervals. Once the initial requirements are not fulfilled anymore, the treatment should be repeated.

\section{Conflicts of Interest}

The authors declare no conflicts of interest.

\section{Acknowledgments}

Financial support of ongoing projects by National Natural Science Foundation of China (51420105015, 51278260), Basic Research Program of China (2015CB655100), and 111 Project is gratefully acknowledged.

\section{References}

[1] H. S. Müller, M. Haist, and M. Vogel, "Assessment of the sustainability potential of concrete and concrete structures considering their environmental impact, performance and lifetime," Construction and Building Materials, vol. 67, pp. 321-337, 2014.

[2] U. M. Angst, R. D. Hooton, J. Marchand et al., "Present and future durability challenges for reinforced concrete structures," Materials and Corrosion, vol. 63, no. 12, pp. 1047-1051, 2012.

[3] H. Huang, G. Ye, C. Qian, and E. Schlangen, "Self-healing in cementitious materials: materials, methods and service conditions," Materials \& Design, vol. 92, pp. 499-511, 2016.

[4] J. Vries, R. B. Polder, and H. Borsje, "Durability of hydrophobic treatment of concrete," in Proceedings of the 2nd International Conference on Water Repellent Treatment of Building Materials, pp. 77-90, Aedificatio Publishers, 1998.

[5] P. Zhang, Y. Cong, M. Vogel et al., "Steel reinforcement corrosion in concrete under combined actions: The role of freezethaw cycles, chloride ingress, and surface impregnation," Construction and Building Materials, vol. 148, pp. 113-121, 2017.

[6] P. Hou, X. Cheng, J. Qian, and S. P. Shah, "Effects and mechanisms of surface treatment of hardened cement-based materials with colloidal nanoSiO2 and its precursor," Construction and Building Materials, vol. 53, pp. 66-73, 2014.
[7] Y. Cai, P. Hou, C. Duan et al., "The use of tetraethyl orthosilicate silane (TEOS) for surface-treatment of hardened cement-based materials: A comparison study with normal treatment agents," Construction and Building Materials, vol. 117, pp. 144-151, 2016.

[8] C. Schröfl, V. Mechtcherine, A. Kaestner, P. Vontobel, J. Hovind, and E. Lehmann, "Transport of water through Strain-hardening Cement-based Composite (SHCC) applied on top of cracked reinforced concrete slabs with and without hydrophobization of cracks - Investigation by neutron radiography," Construction and Building Materials, vol. 76, pp. 70-86, 2015.

[9] J.-G. Dai, Y. Akira, F. H. Wittmann, H. Yokota, and P. Zhang, "Water repellent surface impregnation for extension of service life of reinforced concrete structures in marine environments: The role of cracks," Cement and Concrete Composites, vol. 32, no. 2, pp. 101-109, 2010.

[10] F. H. Wittmann, T. A. J. M. Siemes, and L. G. W. Verhoef, Hydrophobe I, TU Delft, Delft, The Netherlands, 1995.

[11] F. H. Wittmann and A. Gerdes, Hydrophobe II, ETH, Zürich, Switzerland, 1998.

[12] K. Littmann and A. E. Charola, Hydrophobe III, University of Hannover, Hanover, Germany, 2001.

[13] J. Silfwerbrand, "Hydrophobe IV," Stockholm, Sweden, 2005.

[14] H. De Clercq and A. E. Charola, "Hydrophobe V, KIK-IRPA," Brussels, Belgium, 2008.

[15] E. Borrelli and V. Fassina, "Hydrophobe VI," Rome, Italy, 2011.

[16] J-M. Mimoso, “Hydrophobe VII,” Lisbon, Portugal, 2014.

[17] J. G. Dai, H. Yokota, and T. J. Zhao, "Hydrophobe VIII," Hong Kong, 2017.

[18] H. Kus, Long term performance of water repellents on rendered autoclaved aerated concrete [Ph.D. Thesis], Royal Institute of Technology, Stockholm, Sweden, 2002.

[19] A. Gerdes and F. H. Wittmann, "Quantitation of hydrophobic mass by FT-IR spectroscopy," Restor. Build. Monum, vol. 5, pp. 201-210, 1999.

[20] TC 14-CPV Test Method CPC 11.2 Absorption of Water by Concrete by Capillarity, RILEM Publications, 1982.

[21] E. H. Lehmann, A. Kaestner, C. Grünzweig, D. Mannes, P. Vontobel, and S. Peetermans, "Materials research and nondestructive testing using neutron tomography methods," International Journal of Materials Research, vol. 105, no. 7, pp. 664670, 2014.

[22] G. Frei, E. H. Lehmann, D. Mannes, and P. Boillat, "The neutron micro-tomography setup at PSI and its use for research purposes and engineering applications," Nuclear Instruments and Methods in Physics Research, Section A: Accelerators, Spectrometers, Detectors and Associated Equipment, vol. 605, no. 1-2, pp. 111-114, 2009.

[23] P. Zhang, F. H. Wittmann, T.-J. Zhao, E. H. Lehmann, and P. Vontobel, "Neutron radiography, a powerful method to determine time-dependent moisture distributions in concrete," Nuclear Engineering and Design, vol. 241, no. 12, pp. 4758-4766, 2011.

[24] P. Zhang, F. H. Wittmann, M. Vogel, H. S. Müller, and T. Zhao, "Influence of freeze-thaw cycles on capillary absorption and chloride penetration into concrete," Cement and Concrete Research, vol. 100, pp. 60-67, 2017.

[25] P. Zhang, Z. Liu, S. Han et al., "Visualization of rapid penetration of water into cracked cement mortar using neutron radiography," Materials Letters, vol. 195, pp. 1-4, 2017.

[26] P. Zhang, P. Wang, D. Hou, Z. Liu, M. Haist, and T. Zhao, "Application of neutron radiography in observing and quantifying the time-dependent moisture distributions in multi-cracked 
cement-based composites," Cement and Concrete Composites, vol. 78, pp. 13-20, 2017.

[27] GB/T 50082-2009, Standard for Test Methods of Long-term Performance and Durability of Ordinary Concrete, Ministry of Construction, Beijing, China, 2009.

[28] ASTM G 109-07 Standard Test Method for Determining the Effects of Chemical Admixtures on the Corrosion of Embedded Steel Reinforcement in Concrete Exposed to Chloride Environments, American Society for Testing and Materials, Philadelphia, Pa, USA, 2013.

[29] C. Hall, "Barrier performance of concrete: a review of fluid transport theory," Materials and Structures, vol. 27, no. 5, pp. 291-306, 1994.

[30] D. A. Quenard, K. Xu, H. M. Künzel, D. P. Bentz, and N. S. Martys, "Microstructure and transport properties of porous building materials," Materials and Structures, vol. 31, no. 5, pp. 317-324, 1998.

[31] J. Heinrichs, S. Schmeiser, and A. Gerdes, "Numerical simulation of the influence of water repellent treatment on carbonation of concrete," in Proceedings of the 4th International Conference on Water Repellent Treatment of Building Materials, pp. 27-44, Aedificatio Publishers, Stockholm, Sweden, 2005.

[32] ASTM C 876-15 Standard Test Method for Corrosion Potentials of Uncoated Reinforcing Steel in Concrete, American Society for Testing and Materials, Philadelphia, Pa, USA, 2015.

[33] S. Meier and F. Wittmann, "Recommendations for water repellent surface impregnation of concrete," Restoration of Buildings and Monuments, vol. 17, no. 6, pp. 347-358, 2011. 

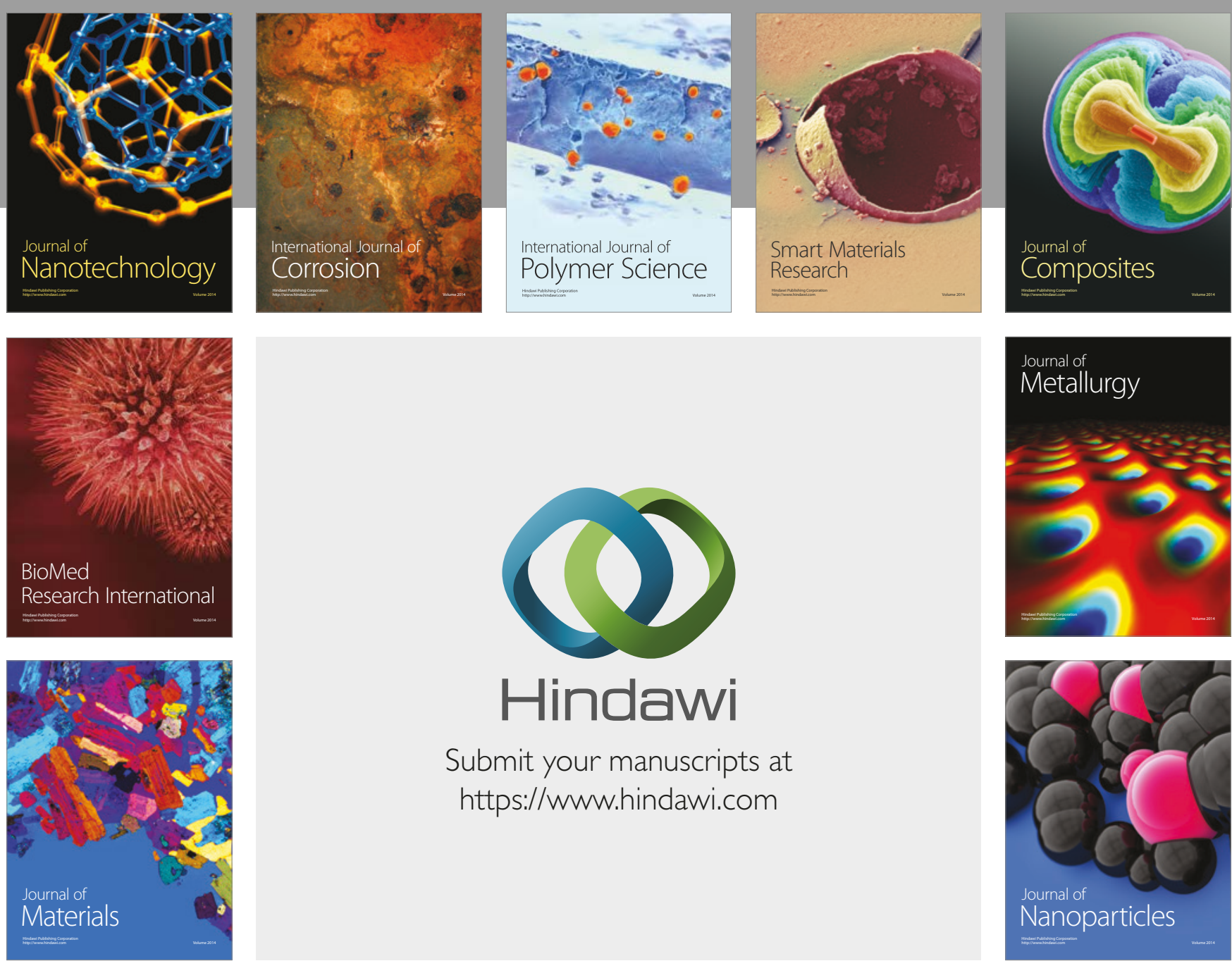

\section{Hindawi}

Submit your manuscripts at

https://www.hindawi.com
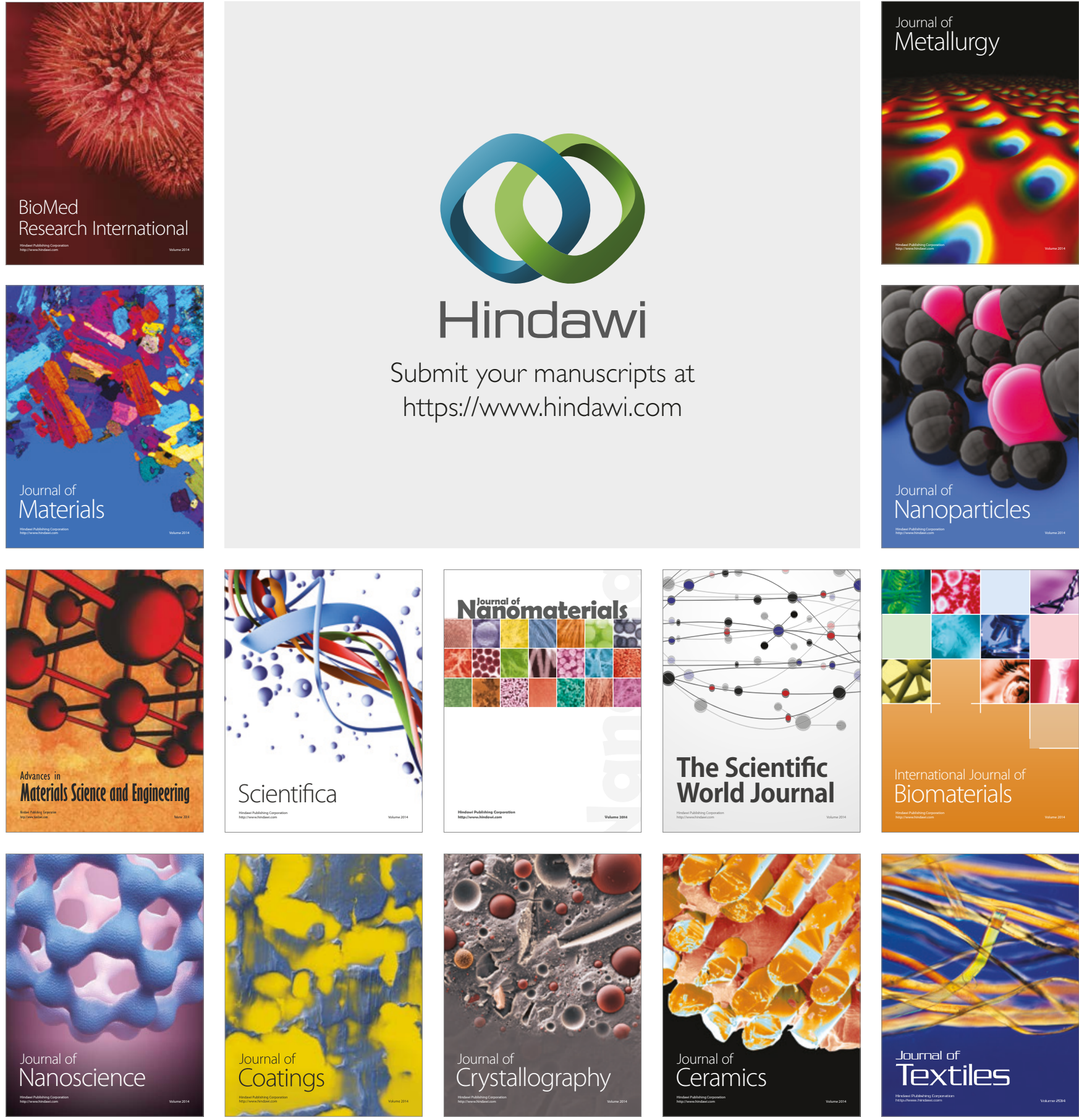

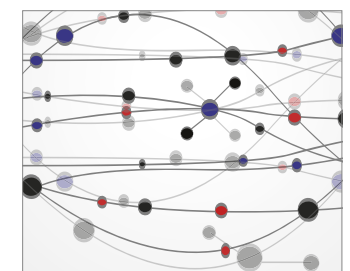

The Scientific World Journal
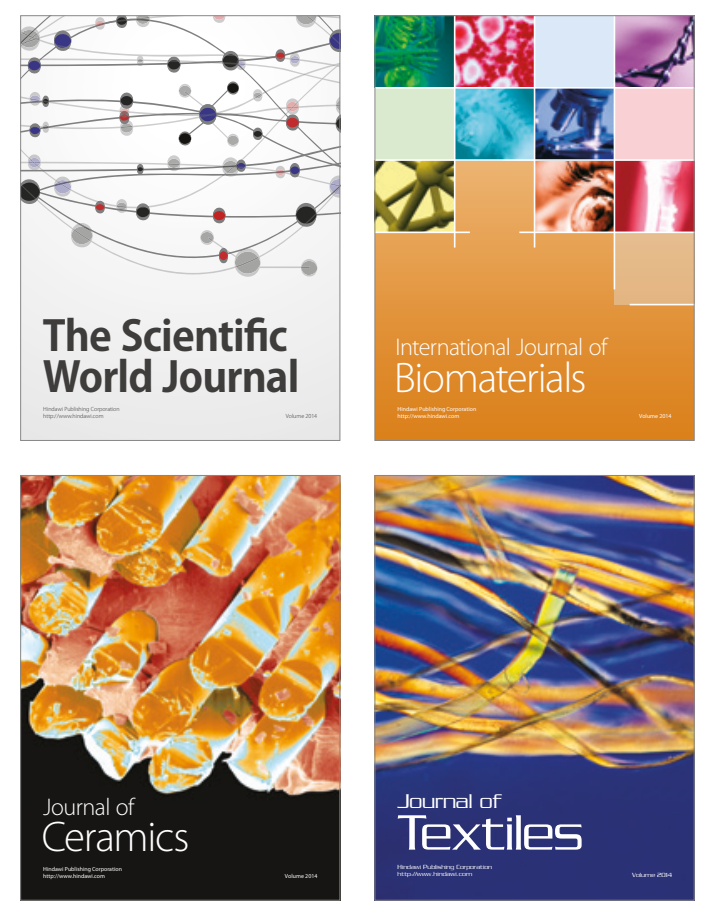